\title{
Sobre a importância e abrangência da análise das proposições condicionais na história da lógica ${ }^{1}$
}

\author{
Concerning the importance and scope of the analysis of \\ conditional propositions in the history of logic
}

\section{Eduardo Simões ${ }^{1}$ \\ Vinícius Martins Corrêa ${ }^{2}$ \\ Walter Ribeiro dos Santos ${ }^{3}$}

\begin{abstract}
1 Professor do Colegiado de Filosofia da Universidade Federal do Tocantins (UFT)
E-mail: eduardosimoes@uft.edu.br ORCID: https://orcid.org/0000-0001-7375-8574

2 Mestrando do Mestrado Profissional em Filosofia PROF-FILO (UFT)

E-mail: vinicius1988@yahoo.com ORCID: http://orcid.org/0000-0002-3321-7172

3 Graduado em Direito e aluno do Curso de Filosofia da UFT

E-mail: amigowalter@yahoo.com.br ORCID: https://orcid.org/0000-0003-4957-9001
\end{abstract}

RESUMO: As proposições condicionais receberam atenção teórica concentrada, embora intermitente, desde a Antiguidade. A atenção durante últimos quarenta anos tem sido intensa. Nesse artigo, apresentaremos os principais desenvolvimentos da análise lógica acerca das proposições condicionais e discutiremos como elas desempenham papel central em muitas teorias filosóficas. Na primeira parte dessas observações introdutórias, mostraremos como os antigos, principalmente as escolas megárica e estoica, envolveram-se com a questão dos condicionais e quão importante isso foi para os posteriores desenvolvimentos da análise lógica dos condicionais no medievo e na Idade Moderna. Por fim, apresentaremos, já na contemporaneidade, C. I. Lewis expondo sua teoria da implicação estrita em franca oposição à doutrina da implicação que ele julgava errada. Espera-se que este trabalho sirva como a apresentação panorâmica de um campo que em lógica ainda é muito frutífero e fecundo para aprofundamentos e novas ideias.

Palavras-chave: Lógica; Condicionais; Validade.

ABSTRACT: Conditional propositions have received concentrated but intermittent theoretical attention since Antiquity. Attention for the last forty years has been intense. In this paper, we will present the main developments of logical analysis of conditional propositions and discuss how they play central roles in many philosophical theories. In the first part of these introductory remarks we shall show how the ancients, especially the Stoic and the Megaric schools, became involved with the question of conditionals and how important this was for the later developments of logical analysis of conditionals in the Middle Ages and in the Modern Age. Finally, we will present, in contemporary times, C. I. Lewis presenting his theory of strict implication in open opposition to the doctrine of implication which he thought was wrong. It is hoped that this work will serve as the panoramic presentation of a field that, in logic, is still very fruitful for deepening and new ideas.

Keywords: Logic; Conditional; Validity.

\footnotetext{
1 Esse artigo é resultado do trabalho de pesquisa do Grupo de Pesquisa "Lógica, Linguagem e Ciência" cadastrado no CNPq e certificado pela UFT.
} 


\section{Os Condicionais na Filosofia Antiga}

Primeiramente, antes de adentrarmos para uma análise histórica dos condicionais, no que concerne à filosofia antiga de início, é preciso uma justificativa breve quanto ao problema dos condicionais no que tange alguns questionamentos que lhes são comuns. A questão que permeia um maior interesse nos condicionais na filosofia dá-se, principalmente, em uma conexão e similaridade entre problemas que cercam a lógica da Antiguidade considerados sob o viés dos mesmos problemas identificados em tempos contemporâneos. Por exemplo, dentro do espectro da verdade e falsidade de uma proposição condicional, que tipo de situação ou estado de coisas a torna verdadeira? Quais condições materiais e/ou lógicas temos para atestar a veracidade de um condicional?

A lógica antiga apesar de ter em Aristóteles um sólido alicerce não foi exatamente fundada com ele. Obviamente, há todo o mérito de uma extensa sistematização advinda do filósofo de Estagira, porém, existem registros mais antigos quanto ao desenvolvimento da lógica na antiguidade. A principal fonte para informações não se encontra nos próprios filósofos antigos, o que dificultou (e ainda dificulta) um maior acesso à lógica antiga por uma via diferente da concepção aristotélica. É a partir do doxógrafo Diógenes Laércio que se obtêm uma visão mais panorâmica a respeito do desenvolvimento da lógica no período.

No que diz respeito ao estudo dos condicionais, temos o início com a escola dos chamados megáricos, começando com Euclides de Mégara. Em sua obra, Diógenes Laércio relata que o filósofo Euclides se dedicou ao estudo de Parmênides e seus seguidores passaram a se chamar megáricos por sua causa, depois erísticos e mais tarde dialéticos (LAÉRCIO, Livro II 10.106)². Os estudos do filósofo Euclides de Mégara sobre a lógica é descrita pelo doxógrafo da seguinte forma:

Ao impugnar uma demonstração, esse filósofo não atacava as premissas, e sim as conclusões. Rejeitava o argumento por analogia, declarando que o mesmo se baseia em coisas similares ou dissimilares; se se baseia em coisas similares, é nestas e não em suas analogias que os argumentos devem basear-se; se se baseia em coisas dissimilares, o paralelo é supérfluo. Por isso Tímon diz dele, atingindo também os outros socráticos: "Não me preocupo com esses tagarelas, nem com outros quaisquer, nem com Fédon, seja ele quem for, nem com o rixento Euclides, que transmitiu aos megáricos o amor frenético pela controvérsia. (LAÉRCIO, Livro II 10.107)

Percebe-se daí um trabalho e construção de uma escola filosófica voltada ao estudo da lógica. Interessante notar, pela anedota da fala de Tímon, uma certa animosidade com a escola megárica pelo dito "amor frenético pela controvérsia". Partindo de Euclides, existem outros nomes de filósofos que representaram a escola megárica no que se refere ao estudo das construções de argumentos e discursos que envolvam a lógica. Porém, na questão sobre os condicionais, o desenvolvimento formal se deu mais tarde com Diodoro Cronus e Filo de Mégara.

Antes de adentrar a questão formal dos condicionais, é preciso dizer que o condicional é um problema na lógica que envolve muito do contexto contemporâneo, porém, há um desenvolvimento prévio desde a idade antiga e que não fora inserido na abordagem aristotélica. Como diz David Sanford (1989), em seu estudo sobre os condicionais, Aristóteles não lida diretamente com o condicional enquanto uma sentença completa, ele lida com termos. O “se $P$, então $Q$ ”, que caracteriza a forma e o aspecto condicional, é diferente de um silogismo clássico aristotélico, composto por três termos.

\footnotetext{
2 “O termo 'dialético' ganha uma concepção de disputa entre os antigos, ganhando a configuração argumentativa de contraposição de discursos, existindo o modo de se pensar e argumentar pela construção de paradoxos. Inclusive importantes paradoxos que serviram para o desenvolvimento da lógica" (KNEALE; KNEALE, 1980, p.116).
} 
Quem desenvolveu e se deteve na questão de se delimitar a abrangência de proposições, declarações ou sentenças como constituintes de sentenças compostas maiores foram os primeiros lógicos estoicos (SANFORD, 1989). Ao analisar o aspecto da forma lógica em Aristóteles se percebe que não há o desenvolvimento de uma lógica sentencial ou proposicional.

Uma questão importante e que estava bem clara aos estoicos, refere-se a uma diferenciação entre uma declaração condicional e um argumento. No exemplo: "Emil foi capturado. Portanto, tudo está perdido. E no condicional correspondente: Se Emil foi capturado, então tudo está perdido” (SANFORD, 1989, p.16), o que se observa é que enquanto a compreensão de um argumento válido é que 'se' as premissas são verdadeiras, 'então' a conclusão também tem de ser verdadeira. No aspecto condicional o funcionamento não está atrelado à validade de qualquer uma das cláusulas (“Se P, então Q", a cláusula "Se P" e a outra cláusula "Q"). É importante salientar que um argumento para ser valido não necessariamente precisa ter as premissas verdadeiras. O que é inviável, num argumento valido, é ter premissas verdadeiras e conclusão falsa. Dito isso, argumentos validos podem ter premissas falsas, ao menos uma, e ainda assim ser valido.

Em O Desenvolvimento da Lógica Kneale e Kneale (1980) apresentam uma certa oposição entre os megáricos e a escola peripatética aristotélica. A distinção de funcionamento das duas abordagens se faz importante para estabelecer o contexto em que a lógica aristotélica prevaleceu durante tanto tempo, relegando os estudos de outras escolas antigas como menos relevantes. Portanto, o desenvolvimento na direção de uma lógica fechada em uma suposta supremacia da linha de raciocínio lançada por Aristóteles fez com que, ao longo da história, a questão dos condicionais ficasse em suspenso.

Para apresentar o aspecto formal dos megáricos, mencionamos novamente Diodoro Cronos e Filo de Mégara. Suas contribuições para a lógica e em especial para a questão dos condicionais, advêm de diferentes posições quanto à possibilidade de inferência corretas através dos condicionais.

O problema que norteia a discussão se insere na questão da validade. Os dois são sistematizadores das possibilidades de o condicional ser considerado verdadeiro. Isso se verifica ao se observar o uso da tabela de verdade, nela é considerada a ideia de Filo como base de cálculo.

O trabalho sobre condicionais se insere na concepção do que é permitido inferir, em critérios que são usados para delimitar a forma correta (verdadeira) do condicional. Os dois filósofos concordam quanto a dizer que: em caso do antecedente (partícula "Se $P$ ") ser verdadeiro, e o consequente (partícula " $Q$ ") ser falso, o condicional como um todo não será verdadeiro.

$\mathrm{Na}$ lógica proposicional de Filo há três possibilidades de o condicional ser verdadeiro e uma única de ser falsa ${ }^{3}$. A discordância de Diodoro não é na forma, mas quanto à semântica. Para ele, a validade só vai ocorrer quando o antecedente não implicar uma conclusão falsa. Em outras palavras, só é verdadeiro o condicional para Diodoro se for impossível de ocorrer um antecedente verdadeiro e um consequente falso. No clássico exemplo do condicional: "Se é dia, eu converso", é possível que seja dia e se esteja em silêncio, ou seja, esse condicional não é verdadeiro para Diodoro, devido haver a possibilidade em algum contexto de o antecedente ser verdadeiro (ser dia) e o consequente ser falso (estar em silêncio). Portanto, há um

${ }_{3}^{3}$ Antecedente verdadeiro e consequente verdadeiro, antecedente falso e consequente verdadeiro, e por fim, antecedente falso e consequente falso são os três casos em que o condicional é considerado válido. 0 único modo do condicional não ser válido é no caso de antecedente verdadeiro e consequente falso.

\begin{tabular}{l|l||l}
$\mathrm{p}$ & $\mathrm{q}$ & $\mathrm{p} \rightarrow \mathrm{q}$ \\
\hline $\mathrm{V}$ & $\mathrm{V}$ & $\mathrm{V}$ \\
\hline $\mathrm{F}$ & $\mathrm{V}$ & $\mathrm{V}$ \\
\hline $\mathrm{V}$ & $\mathrm{F}$ & $\mathrm{F}$ \\
\hline $\mathrm{F}$ & $\mathrm{F}$ & $\mathrm{V}$ \\
\hline
\end{tabular}


componente modal ao se pensar na capacidade ou não de algo ocorrer, ou seja, se determinado condicional é necessário ou possível ${ }^{4}$.

Os relatos que possuímos acerca do que pensavam Diodoro e Filo a respeito de uma lógica modal se encontram em escritos bem mais tardios, como os escritos de Boécio.

Diodoro define o possível como aquilo que ou é ou será (quod aut est aut erit), o impossível como aquilo que sendo falso não será verdadeiro (quod cum falsum sit, non erit verum), o necessário como aquilo que sendo verdadeiro, não será falso (quod cum verum sit, non erit falsum) e o não-necessário como aquilo que ou é já ou será falso (aut jam estt aut erit falsum)5 (KNEALE; KNEALE, 1980, p.120)

As modalidades das frases declarativas se alteram já que o valor de verdade muda. Considerando o exemplo de que: "houve uma revolução francesa". A frase era necessária, mas não era antes da revolução francesa ocorrer. (KNEALE; KNEALE, 1980). Essa posição de Diodoro coloca a questão da validade ou invalidade dentro do aspecto modal. A construção que o filósofo megárico faz a respeito da modalidade abrange uma questão quanto a situação para identificar uma validade. Sendo assim, o que é necessário ou impossível "se modula" e é passível de alteração até atingir tal "status", porém, ao atingir a condição de necessário ou impossível permanece nessa perspectiva

É possível fazer uma ligação com a questão dos condicionais. Um condicional verdadeiro, sob esse prisma, está em uma construção onde não há margem para uma implicação fugir da necessidade de não possuir um antecedente verdadeiro e um consequente falso. Em outras palavras, o impossível de um condicional com antecedente verdadeiro e consequente falso não ocorrerá sob nenhuma hipótese.

Apesar de despontarem como principais expoentes no que diz respeito à questão dos condicionais, travando uma intensa polêmica quanto à correção dos mesmos, há outra escola antiga que também contribuiu bastante para a teoria dos condicionais, e para a lógica de maneira geral, que é a escola estoica: desenvolveram importantes contribuições para a lógica, e também para a teoria dos condicionais, além de referências que remetem à lógica moderna como o cálculo de predicados e lógica modal.

Uma figura de imenso destaque na escola estoica é Crísipo de Sólis. Nos registros de Diógenes de Laércio, esse filósofo grego possui uma extensa lista de obras ${ }^{6}$. E não apenas isso, Crísipo é tido como a principal figura da antiguidade quando o assunto é lógica (dialética).

Esse filósofo conquistou tanta fama na dialética que a maioria das pessoas pensava que se os deuses sentissem necessidade da dialética não adotariam outro sistema senão o de Crísipos. Os argumentos lhe ocorriam copiosamente, porém, seu estilo era imperfeito. Em operosidade Crísipos superava qualquer outro, como o catálogo de suas obras evidencia; com efeito, estas ultrapassam o número de setecentas e cinco (LAÉRCIO, Livro VII, 7.180)

O desenvolvimento da lógica-dialética dos estoicos é posterior aos megáricos e se centra principalmente na figura de Crísipo, que teve papel importante para uma sistematização da lógica. Existe em Crísipo

\footnotetext{
4 É difícil estabelecer uma relação direta entre os conceitos modais antigos e contemporâneos. Tal sistematização teórica pode ser considerada os primórdios de uma certa sistemática modal, que só ganhou mais abrangência no século XX, através das chamadas lógicas não-clássicas, que hoje em dia possuem uma notação e sintaxe próprias para uma base de cálculo.

${ }^{5}$ Commentarii in Librum Aristotelis II , Secunda Editio, ed. Meiser, p.234. Dado a dificuldade de encontrar o original de Boécio, foi escolhido citá-lo a partir do autor que trabalha esse aspecto específico da lógica em sua obra.

${ }^{6}$ Muitas dessas obras se perderam, porém, a listagem de Laércio possui quase 4 páginas para designar as contribuições de Crísipo, dessas 4 páginas apenas 1 delas é dedicada a outro tema (Ética), o restante se refere a uma extensa contribuição para a lógica (LAÉRCIO, Livro VII 7.190-198).
} 
a definição de proposição como "aquilo que é capaz de ser negado ou afirmado em si mesmo”. Os exemplos dados pelos filósofos são proposições como: “é dia” ou "Dion está andando". Na visão do filósofo estoico, o que torna uma proposição verdadeira ou falsa se dá pelo fato da proposição enunciar algo que existe ou não, sendo assim a proposição "é dia", só é verdadeira no caso de realmente ser dia. Outra definição de Crísipo é que toda proposição ou é verdadeira ou falsa e se constituem de dois tipos possíveis: o atômico e o molecular, usando de uma terminologia moderna. Os conectivos apresentados por Crísipo, referentes às proposições moleculares são cinco: o condicional, com conectivo "se", como no caso "se é dia, há luz". O conjuntivo que apresenta o conectivo "e", presente no exemplo "é dia e há luz". A proposição disjuntiva exclusiva, que possui o conectivo "ou”, em que há o exemplo "ou é dia ou é noite”. A quarta proposição chamada de causal - "porque", que se mostra em "porque é dia, há luz". E o último tipo de proposição molecular que não tem um nome específico, mas tem como conectivo "mais provável...que" ou "menos provável...que" (GOULD, 1971). Apesar de interessantes contribuições, que se inserem no contexto de taxonomia, não serão desenvolvidas todas concepções formais de uma lógica estoica que remonta uma correspondência com a linguagem lógica atual, devido fugir ao escopo do artigo, englobando questões alheias ao problema dos condicionais.

No livro de Sexto Empírico sobre Pirro, temos um apanhado das posições quanto ao condicional na antiguidade. Dado a dificuldade de uma boa tradução em português para o autor cético, recorremos a Sanford (1989), que cita uma passagem de Sexto Empírico a respeito das posições quanto ao condicional dos filósofos megáricos e estoicos. Obviamente, estaríamos em melhor situação analisando a partir de obras dos próprios autores megáricos e estoicos. No entanto, o panorama de Sexto Empírico nos dá uma corroboração das posições de Filo e Diodoro quanto uma definição sobre um condicional verdadeiro.

Pois Filo diz que um condicional verdadeiro é um que não tem um antecedente verdadeiro e um consequente falso; por exemplo, quando é dia e eu estou conversando, "Se é dia, então eu estou conversando"; mas Diodoro o define como um que nem é nem nunca foi capaz de ter um antecedente verdadeiro e um falso consequente. De acordo com ele, o condicional mencionado parece ser falso, uma vez que quando é dia e eu fiquei em silêncio, ele terá um antecedente verdadeiro e um consequente falso; mas o condicional que se segue parece verdadeiro: "Se os elementos atômicos das coisas não existem, então os elementos atômicos das coisas existem", uma vez que sempre terá o antecedente falso, "Elementos atômicos das coisas não existem". E aqueles que introduzem conexão ou coerência dizem que um condicional é válido quando a negação de seu consequente é incompatível com seu antecedente; então, de acordo com eles, os condicionais acima mencionados não são válidos, mas o seguinte é verdadeiro: "Se é dia, então é dia". E aqueles que julgam pela "sugestão" declaram que um condicional é verdadeiro se seu consequente é, na verdade, incluído no seu antecedente. De acordo com estes, "Se é dia, então é dia", e cada condicional repetido será provavelmente falso, pois é impossível que uma coisa seja incluída em si mesma. (SEXTO EMPÍRICO, Esboços do Pirronismo, II, 110-12 apud SANFORD, 1989, p. 19, tradução nossa).

A formulação de Filo das condições de verdade aparece logo no começo da citação: "um condicional verdadeiro é um que não tem um antecedente verdadeiro e um consequente falso". Na situação de "ser dia e estar conversando", o condicional é verdadeiro, pois não há um antecedente verdadeiro e um consequente falso. Como já visto, a noção de condicional verdadeiro para Diodoro se dá por uma relação de necessidade, ou seja, é preciso que seja impossível que o antecedente seja verdadeiro e um consequente falso. No exemplo de Sexto Empírico, fica fixado um antecedente falso ("se os elementos atômicos das coisas não existem”), o que acarreta em um exemplo de condicional verdadeiro na perspectiva de Diodoro, devido a situação do antecedente ser falso em qualquer contexto. 
Seguindo para uma terceira definição das condições de verdade do condicional, ela se dá na situação de conexão ou coerência, mesmo que no caso do exemplo se mostre uma tautologia ("Se é dia, então é dia"). Essa forma elimina certos problemas como a situação de duas falsidades desconexas, como o exemplo de: "Se quatro mais quatro são 10, logo Mozart tocava bem piano" (esse condicional de duas falsidades é válido se consideramos Filo e a lógica proposicional moderna). Apesar de não ser explicitado nem a escola, nem mesmo um filosofo em específico, é quase que um consenso atribuir à Crísipo essa terceira concepção de condicional verdadeiro. Segundo o filósofo, uma condicional é verdadeira se a negação do consequente é logicamente incompatível com o antecedente. O que em notação lógica moderna se mostra dessa forma: $(\mathrm{p} \rightarrow \mathrm{q}=$ def. $\sim(\mathrm{p} \wedge \sim \mathrm{q}))$. Há um pressuposto de coesão entre consequente e antecedente, o que remete a implicação estrita moderna, Crísipo busca resolver um problema de seu tempo e se distancia de uma verdade que abstrai o conteúdo do condicional. Ao mesmo tempo, o estoico não restringe a verdade, inexoravelmente, em torno de uma obrigatória relação semântica. Em outras palavras, para Crísipo algo pode ser logicamente possível, mas factualmente impossível (JOHANSEN, 1999).

Cabe aqui nesse momento fazer um parêntese, explicitando que a questão do condicional só ganhou novos contornos com os trabalhos mais modernos no século XX iniciados por C. I. Lewis, conforme veremos adiante ao se abordar a questão dos condicionais na contemporaneidade. Existe, nas análises atuais, uma certa compatibilidade com essa ideia de condicional verdadeiro, atribuída por muitos a Crísipo. Nessas análises, o condicional estrito se assemelha com a noção de conexão ou coerência do condicional. Por mais que se questione a formalização em termos lógicos, que só foram desenvolvidas no século XIX (o que resultaria em um possível anacronismo ao abordar uma simbologia moderna para caracterizar o pouco que temos sobre a lógica antiga), é bastante plausível uma conexão entre a questão do condicional nos tempos antigos e os desenvolvimentos do século XX. Pode-se afirmar que há um resgate de noções já desenvolvidas no período antigo, mas que foram aprimoradas a partir de todo um saber sintático já constituído, um conhecimento que escapava aos antigos ${ }^{7}$.

A quarta definição, é possível atribuir aos peripatéticos, devido no próprio texto indicar a eliminação do condicional tautológico. A forma "Se P, então P”, era considerado uma construção verbal inútil para a escola peripatética, segundo Kneale e Kneale (1980). Apesar de se vislumbrar um quadro progressivo não é possível garantir que haja tal progressividade nas quatro posições apresentadas por Sexto Empírico. É provável que ele tenha escolhido tal ordem de acordo com critérios pessoais, mesmo que tais construções pareçam ser verdadeiras não há um retrato mais pormenorizado dos argumentos utilizados nesse debate.

Diante desse quadro, é possível dizer que a lógica na filosofia antiga passa de uma questão esquecida e negligenciada (o que se deve em grande parte pela primazia da lógica aristotélica, tida como mais prática e funcional), para a importante fonte de saber e produção que auxilia com boas fundamentações e referências para os tempos atuais. Assim, apesar do registro maior se concentrar no período medieval, injustamente qualificado como "Idade das Trevas", o período antigo se mostra bastante rico para a lógica (e para o problema dos condicionais), mesmo diante do pouco material que ficou preservado dessa época, é importante reiterar. Os medievais imprimiram uma maior sistematização na lógica, dentro de um contexto de interseção entre a lógica de Aristóteles e uma lógica anterior na antiguidade, que teve nas escolas megárica e estoica seus maiores expoentes.

\footnotetext{
${ }^{7}$ Essa ideia será melhor desenvolvida no item 4 do artigo.
} 


\section{Os Consequentiae no Período Medieval}

Diferentemente do que se ouve sobre a produção intelectual na Idade Média, que é classificada por muitos historiadores desavisados como a "Idade das Trevas", querendo com isso qualificar esse período como infértil e infrutífero, não é isso que se vê no campo da lógica.

Boécio, o último filósofo da Antiguidade a nos fornecer uma ligação entre a lógica antiga e o que viria a ser o desenvolvimento da lógica na Idade Média, não nos fornece uma inovação para além daquilo que foi tratado sobre os condicionais pelos estóicos. Entretanto, diferentemente de Aristóteles que "usou a forma condicional para exprimir os seus princípios do raciocínio silogístico, mas parece que o fez sem refletir na natureza da frase condicional" (KNEALE; KNEALE, 1980, p. 198), Boécio no trato dos silogismos", apresenta a distinção entre proposições hipotéticas e categóricas, o que servirá como ponto de partida para as especulações dos medievais sobre a implicação. Para as proposições, tal como para os silogismos, ele emprega indiferentemente duas palavras, a saber, hipotéticas e condicionais, e distingue duas espécies de proposições hipotéticas: aquelas em que o consequente está ligado ao antecedente de maneira acidental (consequentia secundum accidens) e aquelas em que o consequente está ligado ao antecedente de maneira natural (consequentia naturae). Essa distinção ficou marcada de tal forma entre os medievais e lhes serviu para as especulações sobre implicação que um "certo lógico moderno" não terá escrúpulos em traduzir a fórmula de Boécio, uno secundum accidens, altero ut habeant aliquam naturae consequentiam por: '1. by material implication, 2. by formal implication"” (BLANCHÉ, 1985, p. 130).

Conforme se disse, a produção intelectual medieval no campo da lógica foi bastante extensa. Houveram tratados sobre os syncategoremata, sobre a suppositio, sobre obligationes, sobre os sophismata, sobre os insolubilia, além de outros, mas é a questão dos consequentiae que nos ocupará aqui, pois podemos de antemão encará-la como a prefiguração de uma parte fundamental e essencial de nossa lógica contemporânea.

Muitos foram os filósofos que se ocuparam da questão da consequentiae. Entretanto, Pedro Abelardo certamente foi a inspiração dos diversos tratados sobre esse tema que apareceram no século XIV. A palavra "consequência", desde Abelardo, passou a designar a proposição condicional, aquela que se inscreve na forma "Se... então...". Segundo ele, uma condicional perfeita é uma verdade em virtude de sua estrutura formal. No entanto, vale ressaltar que, diferentemente da prática comum entre os lógicos contemporâneos em criar uma notação que descreva a forma lógica das proposições, "os lógicos medievais não usavam variáveis para mostrar as formas lógicas que os interessavam e formulavam as regras através de descrições gerais" (KNEALE; KNEALE, 1980, p. 299). Dessa forma, o entendimento de estrutura formal está baseado do fato de que, em frases declarativas condicionais que afirmam a conexão necessária entre os seus componentes, as premissas por si próprias servem para estabelecer as conclusões, isto é, a conclusão de um argumento válido se segue necessariamente das premissas. "Se nós construirmos uma frase declarativa condicional, que tenha como antecedente a conjunção das premissas de um argumento, o resultado é uma consequentia verdadeira secundum complexionem, isto é, é verdadeira apenas em virtude da sua estrutura formal" (KNEALE; KNEALE, 1980, p. 221).

A verdade desses condicionais, portanto, é completamente independente do assunto. Mas, Abelardo também nos apresenta um exemplo de condicional verdadeira que não é perfeita. Por exemplo, se da premissa Socrates est homo inferimos Socrates est animal ou "Se Sócrates é humano, então é um animal” poderíamos

8 Em De syllogismo hypothetico.

9 J. T. Clark, Conventional logic and modern logic, Woodstock, Md. 1952, p. 38. 
ter como representação formas do tipo "Se $P$, então $Q$ " ou “Se a é $G$, então a é $H$ ", mas nenhuma sentença é puramente verdadeira em virtude de ter uma dessas formas. Algumas instâncias são verdadeiras e algumas são falsas. A substituição de "Sócrates" por uma constante de nome ficaria "Se $a$ é humano, então $a$ é um animal”. Essa condicional não é verdadeira segundo a forma, pois “para revelar a conexão entre a cláusula original e a cláusula principal, a 'cláusula se' deveria ser expandida adicionando a verdade necessária que os humanos são animais: 'Se Sócrates é humano e todos os humanos são animais, então Sócrates é animal' (SANFORD, 1989, p. 32).

$\mathrm{Na}$ discussão das consequentiae Abelardo usa várias regras de lógica formal, dentre elas destaca-se aqui aquelas que passaram a chamar mais tarde de modus ponendo ponens (positur antecedente ponitur consequens) e a modus tollendo tollens (perempto consequente perimitur antecedens). "Ao apresentá-las Abelardo diz que cada uma delas pode ser derivada da outra, porque é possível argumentar de Si est homo est animal para Si non est animal non est homo e reciprocamente" (KNEALE; KNEALE, 1980, p. 224). Ele apresenta ainda regras negativas, regras de transitividade da implicação, regras para as relações de verdade e falsidade com a afirmação e negação, regras para a relação das modalidades, regras de consequentiae naturales, regras para as proposições temporais e disjuntivas, etc. O que nos interessa, por ora, é o legado deixado por ele, que influenciará os lógicos que o sucederam, no sentido de apresentar uma lógica onde uma condicional perfeita é uma verdade em virtude de sua estrutura formal.

O Pseudo-Escoto ${ }^{10}$, por exemplo, irá defender que "uma consequência é uma proposição hipotética composta de um antecedente e de um consequente ligados de tal maneira que seja impossível que o antecedente seja verdadeiro e o consequente falso" (BLANCHÉ, 1985, p. 164). Entretanto, o próprio autor apresenta um exemplo evidentemente válido, mas que não satisfaz o seu próprio requisito:

Toda proposição é afirmativa.

Portanto, nenhuma proposição é negativa.

Se a primeira proposição é formulada ao mesmo tempo do que a segunda, são ambas contingentemente falsas e podem, por isso, aparecer respectivamente como antecedente e consequente numa consequentia válida. "Uma vez que a afirmação "Nenhuma proposição é negativa” é, em si, uma afirmação negativa, esta não pode ser verdadeira. Por outro lado, embora "Toda proposição é afirmativa” é, na verdade, falsa, não é necessariamente falsa. Parece ser possível que esta afirmação seja verdadeira” (SANFORD, 1989, p. 36).

Sanford (1989, p. 36), apresenta um princípio da lógica modal para demonstrar que se a premissa é possível e a conclusão impossível, a conjunção da premissa com a negação da conclusão é possível. Eis o princípio: Se é possível que $P$ e impossível que $Q$, então é possível que $P$ e não $Q$.

Isso demonstra ser um erro supor que uma consequentia tem que ser válida se é impossível que quando a consequentia é formulada o estado de coisas referido pelo antecedente tivesse que realizar sem que realizasse o estado de coisas referido pelo consequente. "Devíamos antes dizer que uma consequentia é válida se, para o estado de coisas significado pelo antecedente e para o estado de coisas significado pelo consequente, é impossível que o primeiro fosse realizado sem o segundo" (KNEALE; KNEALE, 1980, p. 293).

O Pseudo-Escoto considera outra definição de validade, a de que "um argumento de premissa única é válido se, e somente se, é impossível que a premissa e a conclusão sejam formuladas juntas, e a premissa seja verdadeira enquanto a conclusão é falsa” (McDERMOTT, 1972, p. 290). No caso do exemplo acima, se "Toda proposição é afirmativa" é formulada juntamente com "Nenhuma proposição é negativa", são

10 Uma edição de 1639 por Luke Wadding de João Duns Escoto (1266-1308) contém muitas obras que não são mais atribuídas a Duns Escoto. Alguns escritos lógicos antes atribuídos a Duns Escoto, agora passam a ser creditados ao Pseudo-Escoto. 
ambas contingencialmente falsas. Podem assim, respectivamente, aparecer como premissa e conclusão em uma consequentia válida. A dificuldade, portanto, estaria em exemplos como este:

Deus existe.

Portanto, esse argumento não é válido.

Aqui, caso se admita que o consequente seja necessariamente verdadeiro, temos uma consequentia inválida que satisfaz à condição de validade exigida acima.

Este argumento é válido ou não? Se for válido, então, uma vez que tem uma premissa verdadeira, tem uma conclusão verdadeira. Mas se a conclusão, que diz que o argumento não é válido, for verdadeira, o argumento não é válido. Então, se o argumento é válido, não é válido. Portanto, não é válido. Mas, agora considere o que segue do pressuposto de que não é válido. Como a conclusão diz que o argumento não é válido, se o argumento não é válido, a conclusão é verdadeira. Mas, se essa conclusão é verdadeira, não há possibilidade de não ser verdadeira. Um argumento no qual a conclusão não tem possibilidade de não ser verdadeira é válido. Então, se o argumento não é válido, é válido. Se não é válido, é; e se for, não é. (SANFORD, 1989, p. 37)

Se se pressupõe que o antecedente é necessariamente verdadeiro, pode-se concluir que a consequentia em seu conjunto é inválida, uma vez que a hipótese que é válida conduz a uma auto-contradição (KNEALE; KNEALE, 1980). São esses modelos de argumentos paradoxais que levaram a produção de diversos tratados sobre insolubilia na era medieval.

Outro filósofo a se preocupar com a questão dos consequentiae foi Guilherme de Ockham. Ele enumerou três pares de distinções entre os consequentiae. O primeiro deles diz respeito à distinção entre consequentiae simplices (o antecedente não pode ser verdadeiro em momento algum sem o consequente) e consequentiae ut nunc (o antecedente pode ser verdadeiro sem o consequente em algum momento, desde que não seja no momento da fala). O exemplo que Ockham dá de consequentiae ut nunc é "Se todo animal corre, então Sócrates corre", afirmado em um tempo em que Sócrates era vivo. A existência atual do animal Sócrates liga as cláusulas da condicional. Nesse entendimento da declaração condicional, o exemplo é falso desde que não haja nenhum animal em torno do nomeado "Sócrates". Com essa divisão, o que Ockham faz é criar uma distinção entre validade absoluta e contingente. "Seja como for que se definam as consequentiae ut nunc, é óbvio que elas só são consequentiae por cortesia e por isso devem-se separar de início das consequentiae absolutas" (KNEALE; KNEALE, 1980, p. 294).

Outra distinção feita por Ockham é entre consequentiae satisfeitas per media intrinseca (por meios intrínsecos) e per media extrinseca (por meios extrínsecos). Extrínseco aqui significa "extrínseco ao assunto do condicional" - uma regra geral que trata tanto dos termos da consequentia como de quaisquer outros. E intrínseco é "uma proposição formada de termos contidos na própria consequentia".

Um exemplo do primeiro gênero de consequentia é, para Ockham "Sócrates não corre, logo um homem não corre" que é satisfeita pelo médium "Sócrates é um homem" e como exemplo do segundo gênero o argumento "Só um homem é um burro, logo todo o burro é um homem” que é satisfeita pela regra geral "Uma proposição afirmativa exclusiva é equivalente a uma proposição universal afirmativa com os termos transpostos" e não precisa de apoio de nenhuma outra proposição, incluindo os termos "homem" e "burro". (KNEALE; KNEALE, 1980, p. 294)

Uma última distinção feita por Ockham é entre consequentiae materiales e consequentiae formales. As formais são aquelas que são satisfeitas por "um meio externo" que dizem respeito às formas das proposições e, ainda, que são satisfeitas diretamente por um "meio interno" e indiretamente por "um meio externo (não) olhando para as condições gerais das proposições, para a verdade, a falsidade, a necessidade a 
impossibilidade". Já a condicional material é satisfeita pelo "significado preciso dos termos e não por causa de algum meio externo que (não) parece precisamente com as condições gerais das proposições”. Os dois exemplos dado por ele são: "Um homem corre, logo Deus existe" (em que se supõe que o consequente é necessário) e "Um homem é burro, logo Deus não existe" (em que se supõe que o antecedente é impossível). Com isso, ele quer demonstrar duas regras por ele admitidas, a saber, "o necessário segue de qualquer coisa" e "qualquer coisa segue do impossível".

Um argumento $P$, portanto, $C$ é válido se, e somente se, for impossível que $P$ e não $C$, isto é, se, e somente se, for necessário que não $P$ e não $C$, então a necessidade de $C$ sozinho ou a impossibilidade apenas de $P$ é suficiente para satisfazer a exigência de validade. Se é impossível que $P$, então é impossível que $P$ e não $C$, não importa o que aconteça, não importa quão irrelevantes e desconexos $C$ e $P$ pareçam estar. Da mesma forma, se for necessário que $C$, então é necessário que não $P$ e não $C$, não importa o que $P$ seja. $O$ ponto correspondente vale para condicionais nas interpretações de Filo ou Crísipo. Qualquer condicional com uma cláusula principal necessária é verdadeira. Qualquer condicional com uma "cláusula se" impossível é verdadeira. (SANFORD, 1989, p. 34)

Depois destas distinções, Ockham formula uma série de regras especiais sobre as consequentiae que são elas ${ }^{11}$ :

$1^{\text {a })} \mathrm{O}$ falso nunca se segue do verdadeiro;

$\left.2^{a}\right) \mathrm{O}$ verdadeiro pode seguir-se do falso;

$\left.3^{a}\right)$ Se uma consequentia é válida, a negação do antecedente segue-se da negação do consequente;

$\left.4^{a}\right)$ Tudo o que se segue do consequente, segue-se do antecedente;

$\left.5^{a}\right)$ Se o antecedente se segue de qualquer proposição, o consequente segue-se também;

$\left.6^{a}\right)$ Tudo o que é consistente com o antecedente é consistente com o consequente;

$7^{\mathrm{a}}$ ) Tudo o que é inconsistente com o consequente é inconsistente com o antecedente;

$\left.8^{a}\right)$ O contingente não se segue do necessário;

$\left.9^{a}\right)$ O impossível não se segue do possível;

$\left.10^{a}\right)$ Qualquer coisa se segue do impossível;

$\left.11^{a}\right)$ O necessário segue-se de qualquer coisa.

Essas regras reaparecem com variações em muitas obras posteriores, especialmente, entre os lógicos contemporâneos, visto que a era moderna acaba por sofrer quase que uma estagnação na produção intelectual no campo da lógica.

\section{Consequência, Condicionais e Insolubilia na Lógica da Idade Moderna}

Com relação ao desenvolvimento da lógica, considera-se a Idade Moderna como o período de transição entre a história do desenvolvimento da lógica formal clássica e o nascimento da lógica matemática. Esse período coincide com o período histórico do Renascimento que, como se sabe, representa uma virada na história do conhecimento e desenvolvimento humanos. Coincide, por consequência, com uma forte reação à ideologia religiosa medieval e, em virtude disso, com um forte ataque ao aristotelismo escolástico, sob todos os vieses teóricos. Em lógica a situação não foi diferente, a lógica genuína foi desprezada e substituída pela retórica. "Dos 400 anos que vão do meio do século XV ao meio do século XIX temos vários manuais de lógica, mas muito poucas obras que contenham alguma coisa que seja ao mesmo tempo, nova e

${ }^{11}$ Essas regras encontram-se em Kneale; Kneale (1980, p. 296). 
boa” (KNEALE; KNEALE, 1968, p. 303). Em virtude da forte retomada da retórica no período renascentista, "a finalidade principal da educação era agora a capacidade de escrever um Latim elegante e para isso Cícero e Quintiliano eram autoridades. (...) até os livros que pretendiam ser acerca de lógica tinham muitas vezes tantas citações de Cícero como de Aristóteles" (KNEALE; KNEALE, 1968, p. 305). Mesmo assim, a lógica formal, que perde o protagonismo que teve na Antiguidade e no período medieval, manteve-se viva em manuais que a reproduziam sem apresentar nada de novo.

Como se sabe, diferentemente dos estóicos e dos megáricos, Aristóteles não desenvolveu uma lógica dos condicionais, preferindo dar ao princípio da condicionalidade algo como óbvio. A lógica moderna, que se fundamentava entre os que desprezavam Aristóteles e aqueles que eram seus partidários, demonstrou pouco desenvolvimento também no que concerne à lógica dos condicionais. Excetuando Juan de Celaya, podemos dizer que nos 400 anos depois da tomada de Constantinopla não tivemos maiores preocupações com a questão dos condicionais entre os modernos.

Sobre de Juan de Celaya, quase nada se encontra na atualidade que diga respeito à sua importância para o desenvolvimento da lógica no início da Idade Moderna. O que nos chegou foi em virtude da persistência de discípulos seus, como Jean Ribeyro e Pierre Gontier, que professavam um verdadeiro culto a Celaya, editando várias de suas obras, mantendo e divulgando seu erário intelectual num "movimento" que representava uma espécie de "escola celayana"12, o qual foi responsável pela manutenção e divulgação do seu erário intelectual. A obra que será considerada adiante é a Insolubilia Magistri Joannis de Celaya conhecida como Tratado da Proposições Insolúveis de Celaya.

A obra Insolubilia constitui o ponto de partida do tratamento da questão dos condicionais em Celaya. Durante os séculos XIV e XV muitos foram os tratados Insolubili ou Insolubilibus que apareceram na literatura medieval $^{13}$. O ponto de partida de todos eles era a busca pela solução do paradoxo do mentiroso, cuja tentativa ocupou até Aristóteles. Tal paradoxo é atribuído ao cretense Epimênides que teria dito que todos os cretenses eram mentirosos. Entretanto, se Epimênides, enquanto cretense, afirma que todo cretense é mentiroso, então (se o que ele diz é verdade), ele também é um mentiroso - se o que ele diz é verdadeiro, então, o que ele diz é falso. Mas, se o que ele diz é falso, então, ele não é mentiroso (os demais cretenses também não). Logo, o que ele diz é verdadeiro. Assim, se o que ele diz é falso, então o que ele diz é verdadeiro (o que resultaria em uma contradição).

Mas, a versão do paradoxo do mentiroso tem outras variantes e sua versão medieval girava em torno da seguinte sentença: "Esta proposição é falsa". Isso quer dizer que, se a proposição é verdadeira, então o que ela diz é o caso; logo, ela é falsa. E, se a proposição é falsa, então o que ela diz não é o caso; logo, ela é verdadeira. Assim, a proposição do Mentiroso e suas variações é verdadeira se, e somente se, for falsa. Mas, ela tem que ser verdadeira ou falsa; e o fato de ser ambas, torna-a uma contradição. O que fazer, então, descartá-la como sendo algo sem sentido? Não parece ser o caso, pois ela é gramaticalmente correta, não é vaga, não é ambígua e não é sem sentido. Mas, uma sentença não é aquilo que pode ser um portador de verdade? Como considerar a sentença do Mentiroso como uma sentença se ela é por si mesma contraditória? Segundo Roure (1962, p. 243), Aristóteles teria dito que "nada impede que o mentiroso, quando diz que está

12 As questões históricas e teóricas acerca do pensamento de Celaya e que se encontram no presente item tem a fundamentação na seguinte obra: ROURE, Marie-Louise. “LE TRAITÉ ‘DES PROPOSITIONS INSOLUBLES' DE JEAN DE CELAYA." Archives D'histoire Doctrinale Et Littéraire Du Moyen Age, vol. 29, 1962, pp. 235-338. JSTOR. Disponível em: www.jstor.org/stable/44403135. Acesso em: 10 jan. 2019.

13 "Um insolúvel é um enunciado que se apresenta de tal modo que, de qualquer modo que se tomem dos contraditórios, segue sempre o contraditório do que foi postulado" (MAGNO, A. Sophistici Elenchi, II, 23, 3, 696B apud ROURE, 1962, p. 243). 
mentindo, diz ao mesmo tempo o verdadeiro e o falso, pois não é impossível que alguém que seja um simplista mentiroso seja verdadeiro a partir de um certo ponto de vista”.

Celaya, ao tratar da questão, define as proposições como reflexivas e as que se falsificam. As proposições reflexivas são aquelas cujo um extremo assume para si a proposição, por exemplo, "esta proposição é falsa" - designando por "esta" a proposição propriamente dita. Já as proposições que se falsificam são aquelas que relacionam "o verdadeiro com o verdadeiro", isto é, "confrontadas com o dado implica sua própria falsidade, enquanto indica que é como é”. A proposição "esta proposição é falsa” cumpre os dois papéis: no caso dado é a única coisa que é declarada e, além disso, é falsa. Celaya assimila as proposições insolúveis às proposições reflexivas e as que se falsificam.

Roure (1962), apesar de assumir que as demonstrações por ela apresentadas "não são encontradas no texto de Juan de Celaya" (p. 257), cria uma notação e formaliza as intenções de Celaya apresentando-nos “a solução" encontrada pelo autor para a questão dos Insolubilia a partir da seguinte demonstração ${ }^{14}$ :

a) Tomemos a proposição reflexiva $p$ "esta proposição é falsa", onde ' $p$ ' designa o nome da proposição;

b) Aqui "Verdadeiro" será simbolizado por V, "Falso" por $\sim \mathrm{V}$, a conjunção "e" por \& e a equivalência por 三;

c) ' $\not$ ' se falsifica se, e somente se, ' $p$ ' é falso e seu significado é $p$. Logo, ' $p$ ' se falsifica $\equiv \sim V$ ' $p$ ' \& $p$;

d) ' $p$ ' é verdadeira $\equiv p$. Sendo "Verdadeiro" o V, temos a primeira definição:

$\mathrm{V} ' p$ ' $\equiv p(\mathrm{I})$

e) ' $p$ ' é falsa $\equiv \sim p$. Sendo "Falso" o $\sim V$, temos a segunda definição:

$\sim \mathrm{V} ' p$ ' $\equiv \sim p(\mathrm{II})$

f) Proposições reflexivas levam, de fato, a paradoxos. Em "esta proposição é falsa”, na qual o sujeito supõe a sua própria proposição, se designarmos por $p$ a proposição e por ' $p$ ' o nome dela, temos:

$p \equiv$ ' $\not$ ' é falsa (em virtude da reflexão) ou $p \equiv$ ' $p$ ' não é verdadeira, o que dá no simbolismo: $p \equiv \sim V$ ' $p$ ' - manifestamente uma contradição;

g) A substituição das fórmulas (I) e (II) pelo seu equivalente V ' $p$ ' dá no seguinte:

Com a fórmula (I): V' $p$ ' $\equiv \sim \mathrm{V}$ ' $p$ '

Com a fórmula (II): $\sim V^{\prime} p$ ' $\equiv \sim(\sim \mathrm{V}$ ' $p$ ') $\equiv \mathrm{V}$ ' $p$ '. Em ambos os casos, há uma contradição.

h) Para resolver o paradoxo, partamos do pressuposto de que ' $\not$ ' existe ou que equivale ao mesmo ' $p$ ' suposto por $p$. Sendo assim, qualquer proposição implica outra proposição estabelecendo que a primeira é verdadeira. A definição de verdade seria, então, formulada da seguinte maneira:

$\mathrm{V} ' p$ ' $\equiv$ ' $p$ ' s $p . \& p$ (III): ' $p$ ' é verdadeiro se, e somente se, suposto por $p$ (' $p$ ' s $p$ ) e significa $p$.

Em outras palavras, para uma proposição ser chamada de verdadeira, não é suficiente que ela seja como significa, ou seja, que tenhamos $p$; é também necessário que esta proposição não implique, pela sua forma, que não é como significa (isto é, não implique que ' $p$ ' não suponha para $p$ ), que é precisamente o caso dos Insolúveis, no qual ' $p$ ' supõe não para $p$, mas para ““ $p$ ” é falso”. (ROURE, 1962, p. 250251)

Para uma proposição ser verdadeira, não é suficiente que seja o que significa, ela também não deve falsificar. Por exemplo,

\footnotetext{
${ }^{14}$ A formalização que a partir de então se apresentada é de inteira responsabilidade de Roure (1962). A não obediência às citações sob a forma da ABNT é para não comprometer a linguagem, que pode ficar confusa, por exemplo, com o acréscimo de aspas em citações curtas. Entretanto, assumimos aqui o débito com a autora, cuja exposição se encontra no texto supramencionado entre as páginas 247 e 253.
} 
a proposição A com o significado $p$ : ““A' é verdadeira se e somente se: 'A' não falsifica e significa p”. Levando em conta a fórmula que propusemos para a proposição que falsifica ( $\sim V^{\prime} A$ ' $\ll p$ - acréscimos nossos) e os símbolos já utilizados para expressar uma proposição verdadeira $\left(V^{\prime} A^{\prime}\right)$ e uma proposição falsa $(\sim V$ 'A'), obtemos:

$\mathrm{V}$ 'A' $\equiv \sim(\sim \mathrm{V}$ 'A'\& $p) \& p$. Pelas leis da dualidade (ou de Morgan):

“ $\sim(p \& q)=\sim p \mathrm{v} \sim q "$ ( $\mathrm{v}=$ 'ou' disjuntivo) obtém-se:

$\mathrm{V}^{\prime} \mathrm{A}$ ' $\equiv(\mathrm{V}$ 'A' $\mathrm{v} \sim p) \& p$. Pela lei da distributividade:

“pvq. \&p$\equiv p \& p . v . q \& p ":$

$\mathrm{V}^{\prime} \mathrm{A}$ ’ $\equiv(\mathrm{V}$ 'A’ \& $p) \mathrm{v}(\sim p \& p)$. (ROURE, 1962, p. 251)

i) A obtenção de V 'A' se dá pela consecução de um dos disjuntivos ao final da citação. Como “ $p$ \& $p$ ” trata-se de uma contradição, é impossível. Daí o primeiro argumento (V 'A' \& $p$ ) se apresenta como uma definição de proposição verdadeira:

$\mathbf{V}$ 'A' $\equiv \mathbf{V}$ 'A' \& $\boldsymbol{p}(\mathbf{I V})$ - “'A' é verdadeiro se, e somente se: 'A' é verdadeiro e tem significação $p$ ”;

j) A definição de proposição falsa seria, portanto, a seguinte:

$\sim \mathbf{V}$ 'A' $\equiv \sim\left(\mathbf{V}\right.$ ' $A^{\prime}$ ' \& $\left.p\right)(\mathbf{V})$ - “'A' é falsa se, e somente se, ela não tiver: 'A' é verdadeiro e tem significação $p$ ”;

k) Usando a segunda parte da definição (V) e da definição (II), temos a seguinte equivalência:

$\sim \mathrm{V}^{`} \mathrm{~A}^{\prime} \equiv\left(\sim \mathrm{V}^{`} \mathrm{~A} \mathrm{~A}^{\prime} \& p\right) \mathrm{v} \sim p$. Pela lei da distributividade, esta fórmula é transformada no seguinte:

$\sim \mathrm{V}^{\prime} \mathrm{A}$ ' $\equiv\left(\sim \mathrm{V}^{\prime} \mathrm{A}\right.$ ' $\left.\mathrm{v} \sim p\right) \&(p \mathrm{v} \sim p)$. O $2^{\circ}$ membro da conjunção " $p \mathrm{v} \sim p^{\prime}$ " é sempre verdade (terceiro excluído), o que permite escrever:

$\sim \mathrm{V}^{\prime} \mathrm{A}^{\prime} \equiv \sim \mathrm{V}^{\prime} \mathrm{A}^{\prime} \mathrm{v} \sim p$. O ato de dualidade de Morgan permite transformar a disjunção acima em conjunção: $\sim \mathrm{V}^{\prime} \mathrm{A}$ ’ $\equiv \sim(\mathrm{V}$ 'A' \& $p$ ). (ROURE, 1962, p. 252)

A fórmula final, obtida através da definição de Celaya é exatamente a fórmula $(\mathrm{V}), \sim \mathrm{V}$ 'A' $\equiv \sim(\mathrm{V}$ 'A' \& $p)$.

Segundo Roure (1962), aplicadas às proposições insolúveis as definições acima apresentadas, tornase possível descartar os paradoxos, estabelecendo que são falsas as suas proposições. A demonstração, segundo a autora, é a seguinte:

Seja a proposição reflexiva "essa proposição é falsa", que designamos por "A", e seja $p$ seu significado. Deve ser determinado se é verdadeiro ou falso. - Vamos supor que é verdade: nós temos, fazendo as substituições apropriadas, a definição da proposição verdadeira (def. IV):

$\mathrm{V}$ 'A' $\equiv \mathrm{V}$ 'A' \& $p$ (IV). Mas $p=\sim \mathrm{V}^{\prime} \mathrm{A}$ ', no caso dado nós temos:

$\mathrm{V}$ 'A' $\equiv \mathrm{V}$ 'A' \& $\sim \mathrm{V}^{\prime} \mathrm{A}$ ', que pode ser escrita também, mantendo apenas uma das duas implicações.

$\mathrm{V}$ 'A' $\rightarrow \mathrm{V}$ 'A' \& $\sim \mathrm{V}$ 'A' (IV-a)

Por " $(p \& q) \rightarrow q$ ", nós temos, fazendo as substituições adequadas:

$\left(\mathrm{V}^{\prime} \mathrm{A}\right.$ ' \& $\sim \mathrm{V}^{\prime} \mathrm{A}$ ') $\rightarrow \sim \mathrm{V}$ 'A' (IV-b)

Por IV-a e IV-b, e a lei “( $(p \rightarrow q . \circlearrowleft . q \rightarrow m) \rightarrow(p \rightarrow m)$ ”, e o esquema de dedução ${ }^{15}$, obtemos:

$\mathrm{V}$ 'A' $\rightarrow \sim \mathrm{V}$ 'A' (IV-c)

Por IV-c e a lei “' $(\mathrm{p} \rightarrow \sim \mathrm{p}) \rightarrow \sim \mathrm{p}$ ” tem-se, finalmente: $\sim \mathrm{V}$ 'A'. (ROURE, 1962, p. 252)

Em outras palavras, se supusermos que a proposição 'A' é verdadeira, somos levados a afirmar que ela não é verdadeira, ou que é falsa.

15 Nós usamos para demonstrações o esquema da seguinte dedução:

Se temos $\mathrm{P} \dashv \mathrm{Q}$

E se tivermos $P$

Nós também temos $Q$ 
A questão das proposições insolúveis, como dito anteriormente, está diretamente relacionada à questão dos condicionais. Na resolução do problema, Celaya acaba por distinguir as boas e as más consequências na discussão da condicional verdadeira e da condicional falsa, que supõem uma distinção entre consequência e condicionalidade.

O conceito de consequência para os antigos significava o que era logicamente válido. Já na Idade Média, especialmente de Ockham, ganhou um significado mais técnico para designar certas proposições de forma condicional. Com os modernos aparece a explícita diferença entre tese e regra de inferência: a proposição condicional é uma tese (uma proposição do sistema que se expressa na linguagem do sistema e que é verdadeira ou falsa) e a consequência é uma regra de inferência (que indica quais derivações são permitidas no sistema). Ao contrário dos medievais, Celaya distingue em sua Insolubilia a consequência da proposição condicional. "Com efeito, ele define primeiro as boas e más consequências (fol $4^{\mathrm{v}} \mathrm{b}$ ), então a verdadeira condicional e a falsa condicional (fol $5^{\mathrm{r}} \mathrm{a}$ ), e ele havia estabelecido anteriormente (fol $2^{\mathrm{v}}$ a) que existem verdades condicionais que são más consequências, e falsas condicionais que têm boas consequências" (ROURE, 1962, p. 255).

Certo é que existem consequências válidas e condicionais verdadeiras, isso, atrelado à noção de sintaxe e semântica, bem como, às noções de leis lógicas e regras lógicas. Celaya não deu conta, assim como os seus contemporâneos, de explicar a diferença entre uma consequência da forma " $a$, portanto, $b$ " e uma forma condicional da forma "Se $a$, então, b", ambas imbricadas em explicações acerca da semântica e sintaxe da linguagem do sistema. Não explicou, além disso, como é possível, ao menos em proposições não-reflexivas, extrair de uma verdadeira condicional (ou de uma implicação) uma regra correspondente em forma de consequência.

Seja a implicação que supomos ser verdadeira: "p $\rightarrow \mathrm{q}$ "16. Se ao mesmo tempo temos "p" verdadeiro, obtemos pelo modus ponens das proposições lógicas:

$p \rightarrow q \& p: \rightarrow q$, o que significa que, quando o condicional " $p \rightarrow q$ " é verdadeiro, se nos damos $p$, também temos $q$. Em outras palavras, se a condicional " $p \rightarrow q$ " é verdadeira, a consequência correspondente " $p$, portanto, $q$ " é válida $(p \dashv q)$. (ROURE, 1962, p. 256)

Nesse sentido, a consequência é válida, ou uma condicional verdadeira, se o antecedente implicar o consequente, isto é, se é impossível se ter o antecedente sem o consequente, o que pode ser simbolizado da seguinte forma:

$$
\begin{aligned}
& \text { "p implica q" se e somente se "p e não-q" é impossível; } \\
& \mathrm{p} \dashv \mathrm{q} \equiv \sim \diamond(\mathrm{p} \& \mathrm{q})(\diamond \equiv \text { é possível, } \sim \diamond \equiv \text { é impossível). }
\end{aligned}
$$

Assim sendo, a consequência estaria mais próxima da implicação estrita de Lewis-Langford (ROURE, 1962, p. 256).

Celaya estabelece que quando se trata de proposições reflexivas, não há mais necessariamente uma correlação entre a consequência condicional válida e verdadeira e demonstra que existem condicionais falsas que são boas consequências.

Roure (1962, p. 256) dá o exemplo de condicional falsa e que é, entretanto, uma boa consequência: "Se esta condicional é verdadeira de acordo com este significado, então o homem é um burro" ("esta condicional" supõe para toda a proposição). Observando que "esta condicional" supõe para "se $p$, então q"

\footnotetext{
16 O símbolo utilizado para a implicação (ou a proposição condicional) é “ $\rightarrow$ ”. Reservamos o símbolo que já utilizado “"” para indicar uma consequência.
} 
temos $p \equiv p \rightarrow q$. Se ' $p$, então $q$ ' é verdadeiro, então $q$, ou “ $p \rightarrow q$. $\rightarrow q$ ". Mas, "o homem é um burro" (o consequente) é falso; da mesma forma, em virtude do modus tollens, o antecedente o será. Logo, teremos $\sim(p$ $\rightarrow$ q) que significa que "se $p$, então q" é falso. Mas, a consequência é boa.

De fato, foi estabelecido que seu antecedente " $p \equiv p \rightarrow q$ " é falso. Além disso, o contraditório de seu consequente, a saber, $\sim q$ (三 o homem não é um burro) é verdade. A conjunção "p \& $\sim$ q" é, portanto, falsa ou impossível, a partir da qual se segue, de acordo com a definição de consequência (ver página 255), que a consequência em questão é boa ou válida. (ROURE, 1962, p. 257)

Mas, também existem condicionais verdadeiras que seriam consequências ruins. O exemplo de Celaya parte da seguinte proposição: "Se esta consequência é boa de acordo com este significado, o homem é um burro" (ROURE, 1962, p. 331). Nesse caso, "esta consequência" assume para a consequência de $p$ para $q$, daí temos: Se $p \dashv q$, então, $q$, ou " $p \dashv q$. $\rightarrow q$ ".

“Mas a consequência dessa implicação ‘o homem é um burro’ é falsa, então o antecedente também é, e assim nós temos: $\sim(p \dashv q$ ), o que significa que a consequência de $p$ para $q$ não é boa" (ROURE, 1962, p. 257). Entretanto, a condicional correspondente é verdadeira, pois para uma condicional ser verdadeira somente se exclui que o antecedente seja verdadeiro e o consequente falso.

Essas demonstrações que, como afirma Roure (1962), não são encontradas no texto de Celaya, na verdade, revelam teses paradoxais do próprio autor. De fato, o raciocínio se refere a duas proposições, uma que é reflexiva (o antecedente), enquanto a outra não (o consequente). Entretanto, o termo "verdadeiro", em ambos os casos, é repleto de ambiguidade. "Para ter certeza de lidar com isso de forma rigorosa e inequívoca, seria necessário ter um simbolismo adequado que permitisse distinguir perfeitamente os diferentes níveis da linguagem" (ROURE, 1962, p. 257). É isso que se espera da lógica de Lewis na contemporaneidade.

\section{A Lógica da Implicação Estrita de C. I. Lewis}

Nessa seção, será abordada a implicação lógica na atualidade, partindo de uma base conceitual e histórica, e adentrando ao sistema de C. I. Lewis.

Hegenberg (1995, p. 120), ao conceituar o termo lógica, esclarece que "desde os tempos de Aristóteles, a lógica (embora ainda não tivesse recebido esse nome) teve delineado seus três objetivos principais", sendo que o terceiro é o mais útil à abordagem que seguirá, ou seja: “[...] usar tais sistemas (e dispositivos) na condição de 'testes' para avaliar a (validade) de argumentos e inferências - quer nas ciências, quer no diálogo do dia a dia".

Para melhor compreensão da implicação lógica na atualidade, que nada mais é do que uma condicional, urge entender a que se aplica e a que se está ligada. Segundo Silva (2009), trata-se de uma nova lógica, simbólica, em contraposição à lógica clássica. Silva (2009, p.30) assevera que "lógica matemática é o nome que designa essa nova lógica”, embora reconheça que o fato de utilizar a palavra matemática, não implica intromissão desta no método da disciplina. Termina por afirmar que "a lógica clássica tinha igualmente por escopo a inteligência desses 'instrumentos mentais', mas o espírito e os métodos da lógica moderna são inteiramente diversos" (SILVA, 2009, p.30).

Frege foi o "divisor de águas" na lógica contemporânea, mas não aceitou como legítima a ênfase na lógica modal, a qual refutou, desde logo, por entender que qualquer coisa que emprega a expressão "ter que" para indicar conhecimento de uma verdade universal em que pode ser deduzida uma proposição, e, de 
maneira análoga, afirme que qualquer coisa seja de certa maneira, admite não conhecer nada que a negação da proposição se siga (KNEALE; KNEALE, 1980).

Coube a Clarence Irving Lewis, em um enfoque pragmático, aproximando-se mais da ação prática do que da filosofia meramente contemplativa, o resgate da lógica modal. Lewis, a fim de abordar os aspectos pragmáticos no estudo da implicação material e opor-se a uma doutrina da implicação que ele julgava errada, extraiu dela os elementos necessários para a superar, elaborando um novo sistema de implicação lógica, a implicação estrita.

Lewis tinha como interesse principal uma implicação mais austera que a implicação material da lógica clássica, superando, assim, problemas da implicação material no que tange aos paradoxos da implicação, ainda que não sejam paradoxos, mas resultados anti-intuitivos. No exemplo de esquemas de fórmulas válidas na lógica clássica: $\alpha \rightarrow(\beta \rightarrow \alpha) ; \neg \alpha \rightarrow(\alpha \rightarrow \beta) ;(\alpha \rightarrow \beta) \vee(\beta \rightarrow \alpha)$, o problema está em ler o operador $\rightarrow$ como implicação. Podendo serem lidas da seguinte forma: uma proposição verdadeira é implicada por qualquer proposição; uma proposição falsa implica qualquer proposição; dadas duas proposições quaisquer, a primeira implica a segunda, ou a segunda implica a primeira, respectivamente como representado nos esquemas (MORTARI, 2001).

A implicação material da lógica clássica é anti-intuitiva, dentre outras coisas, por apontar para o resultado de uma situação paradoxal onde, se o antecedente de um argumento é falso e o consequente também o é, ainda assim, a implicação é verdadeira. Se "o papa é evangélico" então "Dalai-lama é cristão" $(\alpha \rightarrow \beta)$, sendo ambas falsas, terá como resultado a verdade, isso porque, esse argumento equivale a dizer que não é verdade que "o papa é evangélico" e "Dalai-lama não é cristão" $\neg(\alpha \wedge \neg \beta)$. A saída de Lewis foi pensar um conceito mais forte: uma fórmula $\alpha$ implica uma fórmula $\beta$ se não é possível ter $\alpha$ e $\neg \beta$. Tendo sido chamada por ele implicação estrita, assim definida: $(\alpha \prec \beta) \leftrightarrow \neg \diamond(\alpha \wedge \neg \beta)$ (MORTARI, 2001).

Kneale e Kneale (1980) assinala que o interesse de Lewis era defender que a dedutibilidade da conclusão, partindo de um argumento válido, é dependente da satisfação de uma relação estrita que não admite ser definida em termos de função de verdade.

Convém esclarecer que toda implicação estrita é uma implicação material, mas nem toda implicação material é uma implicação estrita. Pergunta-se então: o que é implicação material? Conforme Hegenberg (1995, p. 134), trata-se de regra na qual “o condicional 'Se p, então q’ só é falso quando o antecedente p for verdadeiro e o consequente q for falso [...] a estrita só é admissível dizer 'Se A então B, quando o B' for deduzível de A".

A importância de Lewis é que, em sua abordagem, além de ressuscitar implicação estrita diodoriana, lança mão de um pensamento inovador, examinando aspectos lógicos associados a conceitos como os de necessidade, possibilidade e impossibilidade (e correlatos) ${ }^{17}$. Em seu livro Survey of Symbolic Logic (1918), sintetiza por meio da lógica modal as implicações lógicas de caráter mais restritos que as implicações materiais, embora tenha lançado mão dos trabalhos de Bertrand Russell - Principia Mathematica (1913). No quinto capítulo do livro, Lewis enfatiza que os sistemas discutidos nos capítulos anteriores, ou seja, do I ao IV foram baseados nas implicações materiais, onde, p $\subset$ q significa exatamente: "p é verdadeiro e q é falso, explicando ainda a divergência da implicação da inferência ordinária exibida em determinados teoremas como uma falsa proposição implica qualquer proposição, e uma verdadeira proposição é implicada de qualquer proposição (LEWIS, 1918).

17 Convém rememorar que a lógica modal não é invenção ou descoberta moderna, pois também foi estudada desde Aristóteles (HEGENBERG, 1995, p. 126). 
Lewis tem como objetivo apresentar um cálculo de proposições no qual se baseia em um sentido inteiramente diferente. Esclarece que deverá referir-se à implicação material como sendo aquela de dois valores de álgebra ou de cálculos de proposições como aparece em Principia Mathematica. Alerta, ainda, que parecerá que "as implicações estritas não são cálculos de extensão, como as implicações materiais e a álgebra de Boole-Schröder, nem um cálculo de intenção, como malsucedido sistema de Lambert e Castillon" (LEWIS, 1918, p. 291). Enfatiza que "a implicação estrita contém implicação material, como aparece em princípio na matemática, como um sistema parcial” (LEWIS, 1918, p. 291). Deixa, entretanto, para o final do capítulo a discussão sobre o significado exato de implicação.

Na primeira sessão do Capítulo V, Lewis (1918, p. 292) discute as ideias primitivas, as proposições primitivas e as consequências imediatas. Como ideias fundamentais da lógica simbólica, apresenta para composição do sistema o que segue:

1. Proposições: p, q, r, etc.;

2. Negação: $-p$, significa: "p é falso";

3. Impossibilidade: p, significa: "p é impossível”, ou "é impossível que p seja verdadeiro";

4. O produto lógico: p X q ou pq, significa: "p e q ambos", ou "p é verdadeiro e q é verdadeiro";

5. Equivalência: $\mathrm{p}=\mathrm{q}$, a relação definida.

Como elementos básicos para compreensão do sistema, faz também a observação de que se adiciona as ideias de falso e verdadeiro também à ideia de impossibilidade, assim não mais haverá dois valores a serem calculados, mas 5 valores de verdade, a saber:
a) $p$, " $p$ é verdadeiro";
b) $-p$, " $p$ é falso"
c) $\sim p$, " $p$ é impossível";
d) $-\sim p$, "é falso afirmar que é impossível", por extensão, "p é possível”;
e) - $p$, "é impossível que p seja falso", por extensão, "p é necessariamente verda- deiro".

Argumenta ainda que "as duplas relações de proposições podem ser definidas em termos nesses valores de verdade e produtos lógicos, pq” (LEWIS, 1918, p. 293). Assim, passa a numerar as sete definições de duplas relações conforme segue lista abaixo:

$$
\begin{aligned}
& 1.01 \text { consistência }-\mathrm{p} \circ \mathrm{q}=-\sim(\mathrm{pq}) \text { Def. } \\
& \text { 1.02 Implicação Estrita. } \mathrm{p} \prec \mathrm{q}=\sim(\mathrm{p}-\mathrm{q}) \text {. Def. } \\
& \text { 1.03 Implicação Material. } \mathrm{p} \subset \mathrm{q}=-(\mathrm{p}-\mathrm{q}) \text {. Def. } \\
& \text { 1·04 Adjunção lógica Estrita. } \mathrm{p} \wedge \mathrm{q}=\sim(-\mathrm{p}-\mathrm{q}) \text {. Def. } \\
& \text { 1·05.Adjunção Lógica Material. } \mathrm{p}+\mathrm{q}=-(-\mathrm{p}-\mathrm{q}) \text {. Def. } \\
& \text { 1.06 Equivalência Estrita. }(\mathrm{p}=\mathrm{q})=(\mathrm{p} \prec \mathrm{q})(\mathrm{q} \prec \mathrm{p}) \text {. Def. } \\
& \text { 1.07 Equivalência Material. }(\mathrm{p} \equiv \mathrm{q})=(\mathrm{p} \subset \mathrm{q})(\mathrm{q} \subset \mathrm{p}) \text {. Def. }
\end{aligned}
$$

Lewis (1918, p. 293) explica a primeira definição: (pq), "é impossível que p e q sejam ambos verdadeiros", seria “p e q são inconsistentes”, consequentemente, - (pq), “é possível que p e q sejam ambos 
verdadeiros", representação "p e q são consistentes".

Assim, pq, $(q \subset$ p), $(p+q), e p \equiv q$ são as relações que representam cálculos de implicações materiais, enquanto p o q, p $\prec$ q, p $\wedge$ q, p = q, são relações que não pertencem aos sistemas de implicação material, mas podem ser chamadas de "relações restritas", conforme explica Lewis (1918, p. 293).

No Survey of symbolic logic, Lewis (1918, p. 294, grifo nosso) apresenta como postulados do sistema aqueles de 1.1 a um 1.8, sendo os dois últimos distintos e acrescidos em relação à implicação material, como segue: " $1 \cdot \mathbf{7} \sim \mathrm{p} \prec-\mathrm{p} \quad$ (Se é impossível que $\mathrm{p}$ seja verdadeiro, então $\mathbf{p}$ é falso); $\mathbf{1 \cdot 8} \mathrm{p} \prec \mathrm{q}=\sim \mathrm{q} \prec \sim \mathrm{p}$ ( $\mathbf{p}$ verdadeiro que implica estritamente $\mathbf{q}$ verdadeiro é equivalente a: é impossível que $\mathbf{q}$ verdadeiro implique a impossibilidade de $\mathbf{p}$ verdadeiro)".

Os postulados 1.7 e 1.8 trazem os princípios de transformação: “eles operam sobre outros postulados, e sobre si mesmos, e assim introduzem a distinção característica do sistema". Ao retirar os parênteses é importante lembrar precedência dos sinais e a convenção elaborada por Lewis $(1918,295)$ : "[...] o sinal = [...] tem aqui prevalências sobre qualquer outra relação". Um exemplo: o anzol $\prec$ (que simboliza a implicação estrita) e tem precedência sobre $\subset$ (a ferradura, que simboliza a implicação material - nesse caso não se encontra invertida, por tentar, o presente texto, acompanhar a representação tipográfica utilizada pelo autor). Seguindo a regra de precedência, temos os mencionados sinais de implicação com precedência sobre ${ }^{\wedge}$ (adjunção estrita), + (adjunção material), o (consistente com), etc.

Ao tratar das operações de derivação dos postulados para obter os teoremas, Lewis (1918, p. 295) ressalta que as operações das quais os teoremas são derivados dos postulados são três:

Substituição. Qualquer proposição pode ser substituída por p ou q ou r, etc. Se p é uma proposição, $-p$ e $\sim p$ são proposições; se p e q são proposições, pq é uma proposição. Também qualquer par de expressões relatada de equivalência, também podem ser substituídas pelas outras.

Inferência. Se p é afirmado p $\prec$ q é afirmado, então q pode ser afirmado. (Observe que esta operação não é afirmada por uma implicação material, $\mathrm{p} \subset \mathrm{q})$.

Produção. Se p e q são separadamente afirmados, pq podem ser afirmadas (pq juntos). Esta é a única operação realizada usando uma prova.

A partir desse ponto Lewis (1918, p. 295) passa a calcular seus Teoremas Fundamentais, a exemplo: $2.1 \mathrm{pq} \prec \mathrm{p} ; \quad 1.6$ [pq/p; qp/q; p/r]: 1.1 X $1.2 \prec(\mathrm{pq} \prec \mathrm{p})$.

A prova acima descrita pode ser lida da seguinte forma (LEWIS, 1918, p. 295): "proposição 1.6, quando pq é substituído por p, qp por q, e p por r, prova que as proposições 1.1 e 1.2 juntas implicam (pq $\prec$ p). O número da proposição a qual confirma qualquer linha da prova é dado no início da linha. Depois, em reforço, é feita a indicação de qualquer substituição a ser realizada.

Outro teorema fundamental (LEWIS, 1918, p. 297): $2.2(\mathrm{p} \prec \mathrm{q}) \prec(\sim \mathrm{q} \prec \sim \mathrm{p}) ; 1.06: 1.8=[(\mathrm{p} \prec \mathrm{q}) \prec$ $(\sim \mathrm{q} \prec \sim \mathrm{p})][(\sim \mathrm{q} \prec \sim \mathrm{p}) \prec(\mathrm{p} \prec \mathrm{q})](1) ; 2.1:(1) \prec$ Q.E.D.

Pode-se extrair a seguinte leitura da primeira linha da prova (1) (LEWIS, 1918, p. 297), aplicando-se a definição de dupla relação 1.06 no postulado 1.8 tem-se o produto do enunciado de sua réplica com os termos antecedentes e consequentes invertidos, sendo que se aplicando o teorema 2.1 na linha (1), o produto implica seu primeiro termo, que é o Quod erat demonstratum (Q.E.D.) ${ }^{18}$.

Mais adiante, demonstra como surge o modo necessidade em seu sistema, a partir do teorema 4.1, como se demonstra:

18 Ou seja, como se queria demonstrar, em português utiliza-se a sigla C.Q.D. 


$$
\begin{aligned}
& 4.1 \sim-\mathrm{p} \prec \mathrm{p} \\
& 1.7\{-\mathrm{p} / \mathrm{p}\}: \sim-\mathrm{p} \prec-(-\mathrm{p}) \\
& \text { 2.51: (1) = Q.E.D. } \\
& \text { Se } \mathrm{p} \text { é necessário, então } \mathrm{p} \text { é verdadeiro. }
\end{aligned}
$$

O autor segue as demonstrações dos teoremas que constituem seu sistema, fazendo um paralelo entre as implicações estritas e as implicações materiais, explicando as diferenciações entre as disjunção estrita e disjunção material, faz um paralelo entre as relações de equivalência estrita e material, dentre outros feitos, mencionando que todos os postulados e teoremas de Implicação Material podem ser derivados de postulados e definições de Implicação Estrita (LEWIS, 1918, p. 314).

Seu trabalho mais atual sobre lógica modal é encontrado no livro Symbolic logic, publicado com H.C. Langford em 1932. Nessa última fase do lógico traz algumas alterações tanto na escolha dos simbolos a serem utilizados, bem como faz uma reformulação dos postulados. Em virtude disso, Kneale e Kneale (1968, p. 555) comentam: "Aqui o simbolo $\diamond$ é tomado como indefinido e $\mathrm{P} \prec \mathrm{Q}$ é introduzido como uma abrevidatura de $\sim \diamond(\mathrm{P} . \sim \mathrm{Q}) "$.

Finaliza o capítulo V de sua obra sistematizadora inicial, informando que uma proposição impossível implica qualquer outra; uma proposição necessária é implicada de qualquer outra; também que a falsa proposição implica qualquer outra e a proposição verdadeira é implicada por qualquer outra. Todavia, sobre o significado das implicações, não demonstra o interesse em conceituar o que seja o termo implicação, mas enfatizar a necessidade de que as implicações realizadas em determinado corpo lógico guardem o campo de significação apropriado (LEWIS, 1918).

Nesse sentindo, as implicações devem ter significados apropriados, sem os quais não há possibilidade de se validar, sem qualquer referência de provas adicionais. Sua colocação é pertinente e faz sentido no âmbito das implicações, principalmente para a legitimação do sistema de implicação estrita e a força do condicional.

\section{Considerações finais}

Por fim, resta evidente que a análise das proposições condicionais ao longo da história consiste em importante exercício ao pensamento lógico, não obstante os vários enfoques e divergências encontradas tanto na lógica tradicional como na contemporaneidade. O salto temporal e epistemológico realizado no presente artigo, no sentido de transpor o paradigma sedimentado em torno do entendimento da lógica modal mais difundida, ou seja, a aristotélica, não impediu o registro, embora restrito, do entendimento megárico, em especial, representado na lógica simbólica por C.I. Lewis, que, em diálogo produtivo com o pensamento de Diodoro, propôs um condicional que evite o paradoxo lógico e não seja anti-intuitivo, por meio da implicação estrita. Fica, de igual modo, demonstrado que a análise das proposições condicionais tem uma ampla abrangência no campo da lógica, seja por razão espaço-temporal, seja por razão da diversidade de entendimentos sobre o assunto, ou pela finalidade (dialética ou matemática), cabendo ao estudioso um grande esforço na investigação e aprofundamento sobre tema.

\section{Referências}

BLANCHÉ, Robert. História da Lógica de Aristóteles a Bertrand Russell. Trad. António J. Pinto 
Ribeiro, Lisboa: Edições 70, 1985. (O Saber da Filosofia)

GOULD. J. B. The Philosophy of Chrysippus. Amsterdam:Leiden E. J. Brill, 1971.

HEGENBERG, Leonidas. Dicionário de Lógica. São Paulo: EPU, 1995.

JOHANSEN, K. Friis. A History of Ancient Philosophy. Nova York: Routledge, 1999.

KNEALE, W.; KNEALE, M. O Desenvolvimento da Lógica. 2. ed. Trad. M. S. Lourenço. Lisboa: Fundação Calouste Gulbenkian, 1980.

LAÊRTIOS, Diôgenes. Vidas e doutrinas dos filósofos ilustres. Brasília: Unb, 2008.

LEWIS, Clarece Irving (1918). A Survey of Simbolic Logic. Berkley: University of California Press, 1918.

McDERMOTT, A. C. Notes on the assertoric and modal propositional logic of the Pseudo-Scotus, Journal of the History of Philosophy, 1072, v. 10, p. 273-306.

MORTARI, Cezar A. Introdução à lógica. São Paulo: Editora UNESP, 2001.

ROURE, Marie-Louise. “LE TRAITÉ ‘DES PROPOSITIONS INSOLUBLES' DE JEAN DE CELAYA.” Archives D'histoire Doctrinale Et Littéraire Du Moyen Age, vol. 29, 1962, pp. 235-338. JSTOR. Disponível em: www.jstor.org/stable/44403135. Acesso em: 10 jan. 2019.

SANFORD, David H. If $P$, then Q: conditionals and the foundations of reasoning. London: Routledge, 1989. (The problems of philosophy)

SILVA, Vicente Ferreira da Silva. Lógica Simbólica. São Paulo: É Realizações, 2009. (Coleção Filosofia Atual)

Artigo recebido em: 12 de julho de 2020

Artigo aceito em: 28 de setembro de 2020 